\title{
Popular Backyard Flock program reduces biosecurity risks of amateur production
}

by Sarah Stinson and Aslı Mete

The California Animal Health and

Food Safety laboratories provide free necropsy (postmortem examination) services to owners of backyard poultry through the Backyard Flock program funded by the California Department of Food and Agriculture. We collected and analyzed data on the number of poultry submissions to the program between 2007 and 2012, the lab totals by location and the diseases diagnosed. During those 6 years, submissions increased $383 \%$, with chickens representing $91 \%$ of them, and the greatest increases occurred in Santa Clara, Los Angeles and Sonoma counties. The necropsy data showed that the digestive (32.5\%) and hemolymphatic (16.9\%) systems were the most commonly affected. Marek's disease accounted for $13.3 \%$ of diagnoses (492 cases). With the rapid rise in the number of poultry being raised by amateur producers, biosecurity education is essential.

$\mathrm{T}$ he popularity of backyard flocks has steadily increased over the past several years (Crespo and Shivaprasad 2008; Pollock et al. 2012). Sunset magazine listed backyard chickens as one of the "Top 100 Cultural Trends Shaping the West" in 2011 (Sunset 2011), and the number of websites, blogs and magazines devoted to urban chickens has increased exponentially. Membership of BackyardChickens.com, a popular website and discussion forum, grew from 1,000 in 2007 to over 115,000 by January 2011, with more than 7 million posts by site users (Ludlow 2012). Another popular site, MyPetChicken.com, boasts of receiving tens of millions of page views per year (Torres 2012).

These websites provide a community forum for advice on everything from breed selection to coop construction and

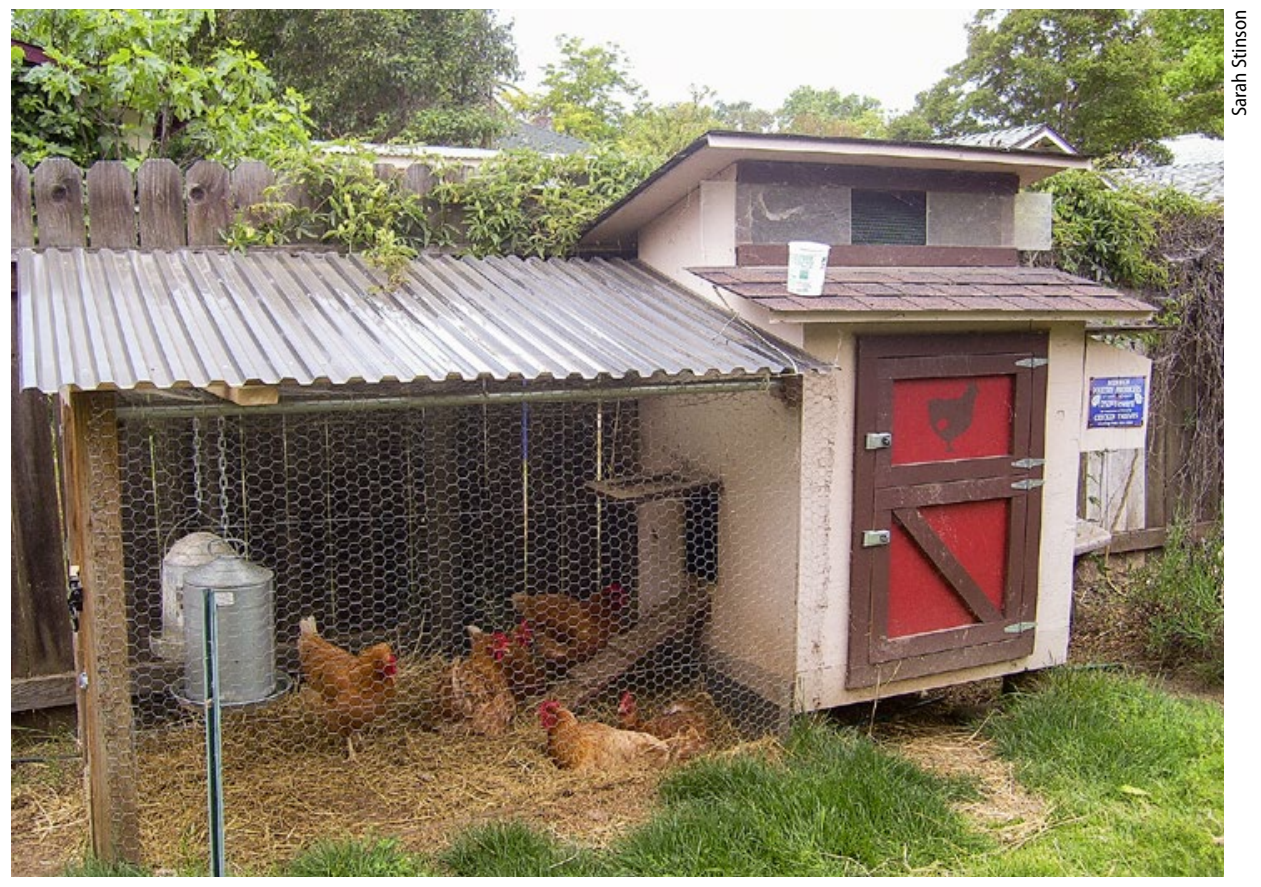

The Backyard Flock program encourages backyard poultry owners to submit dead birds for postmortem examination. The program monitors for diseases that could devastate California's commercial poultry industry.

veterinary care. They also provide information on how to lobby for changes to local ordinances to allow the keeping of backyard poultry in urban areas (Palermo 2010). Such public lobbying has resulted in widespread changes to many ordinances, including, for example, in Sacramento County, where the grassroots organization CLUCK, the Campaign to Legalize Urban Chicken Keeping, has pushed the issue to the forefront of local politics (Cary 2009). A Sacramento city ordinance was amended in 2011 to allow the legal ownership of up to three hens (Sacramento City Code § 9.44.860) in urban neighborhoods.

The rapid rise in the number of poultry being raised by amateur producers with no education on biosecurity (the protection of agricultural animals from infectious agents) is creating an increased risk of the transmission of infectious diseases, both to other backyard flocks and ultimately to commercial flocks as well. The Backyard Flock program offered through the California Animal Health and Food Safety (CAHFS) laboratory system provides owners of backyard flocks with valuable diagnoses and disease information at no charge. This information improves flock management and biosecurity and is also invaluable for tracking disease trends and statistics within a population from which it is difficult to collect data.

\section{Federal, state, local regulation}

The U.S. Department of Agriculture (USDA) regulates aspects of the noncommercial industry related to disease prevention under the Poultry Products Inspection Act (21 U.S.C. $\S 451$ et seq.) and the Egg Products Inspection Act (21 U.S.C. $\S 1031$ et seq.). The California Department of Food and Agriculture (CDFA) regulates poultry in California in much the same way. Under specific circumstances in which a foreign animal disease is suspected, the CDFA (in conjunction with the USDA) has the authority to quarantine and, if necessary, to destroy potentially infected animals (CDFA 2006). This authority is reserved for serious threats to biosecurity and consumer safety, such

Online: http://californiaagriculture.ucanr.edu/ landingpage.cfm?article=ca.v067n04p203\&fulltext=yes doi: 10.3733/ca.v067n04p203 
for one or two birds is performed at no charge to the owner; the cost is covered by CDFA. The information obtained from the necropsies is invaluable for monitoring the disease distribution in and statistical data of a relatively unregulated population. In our research project, we conducted a retrospective analysis of the data to define and assess the scale of the Backyard Flock program and its locations, and summarized the diagnostic findings.

\section{Data review}

Data from avian necropsy cases submitted from backyard flocks (any flock of $<1,000$ birds) in the CAHFS laboratory computer database (STARLIMS 10.5.67) were compiled and analyzed. When an animal is submitted for a necropsy examination, a submission form is filled out by either the flock owner or veterinarian. It is then assigned a unique number in the computer system. The form captures information such as flock size, history and location. Submissions that qualify for the Backyard Flock program are categorized separately, and we extracted our data from those submissions for the period between Jan. 1, 2007, and Dec. 31, 2012, including all CAHFS laboratory locations. SQL (Structured Query Language) and Crystal reports were used to extract data based on the following parameters:

1. Total number of Backyard Flock submissions processed by all laboratories from Jan. 1, 2007, to Dec. 31, 2012.

2. Total number of avian submissions processed during this time period that were not covered by the program (pet birds, birds from large commercial producers, racing pigeons, etc.).

3. Number of Backyard Flock submissions received from each county per year from 2007 to 2012.

4. Species type submitted.

5. Cases given a structured diagnosis (SD), which indicates the primary necropsy finding by the examining pathologist. These cases were categorized according to the affected organ system, and etiologies were recorded when available. The traumatic and nutritional/toxicosis groups of conditions were regarded as separate categories and not included in the organ system grouping, since in these cases there were multiple organ systems affected and they were mostly not reported.
Statistical analysis of the data was performed using a chi-square test (Rosner 2000).

\section{Disease findings}

Over the 6-year period, CAHFS received 19,539 avian submissions, 2,775 of which were Backyard Flock submissions, a significantly large percentage of all avian submissions, with a $P$ value of $<0.0000001$, increasing significantly from $3.6 \%(n=173)$ in 2007 to $30.9 \%(n=835)$ in 2012 (fig. 1). Chickens represented 91\% $(n=2,532)$ of all Backyard Flock submissions during this time period. A $43 \%$ decrease in overall avian submissions was also observed within this period (fig. 1). The distribution of submissions by county is shown in figure 2; Santa Clara, Los Angeles and Sonoma counties had the largest increases.

A total of 3,708 SDs were entered for Backyard Flock cases (some cases had multiple SDs in situations where more than one disease was present or more than one individual carcass was submitted under one submission number).
Analysis of those cases according to affected organ systems showed digestive $(32.5 \%)$ and hemolymphatic $(16.9 \%)$ systems being the most commonly affected (fig. 3). Marek's disease, which was included in the hemolymphatic system, accounted for 492 cases, $13.3 \%$ of the total. The number of cases entered as unexplained death was $72(1.9 \%)$. The observed disease conditions reported as SDs in correlation to affected organ system and etiologies when available were as follows: Digestive system diseases $(n=1,204)$ were bacterial infections (clostridial, mycobacteriosis, salmonellosis, staphylococcosis), parasitic infections (coccidiosis, nematodiasis, trichomoniasis, cestodiasis), neoplasia, fatty liver syndrome, intestinal volvulus and intussusception, and foreign body ingestion and obstruction. Hemolymphatic system diseases $(n=$ 628) were lymphoproliferative diseases, infectious bursal disease and bursal cryptosporidiosis. Cardiovascular system diseases $(n=82)$ were ascites syndrome, vitamin E deficiency, Streptococcus species and Escherichia coli infections, and

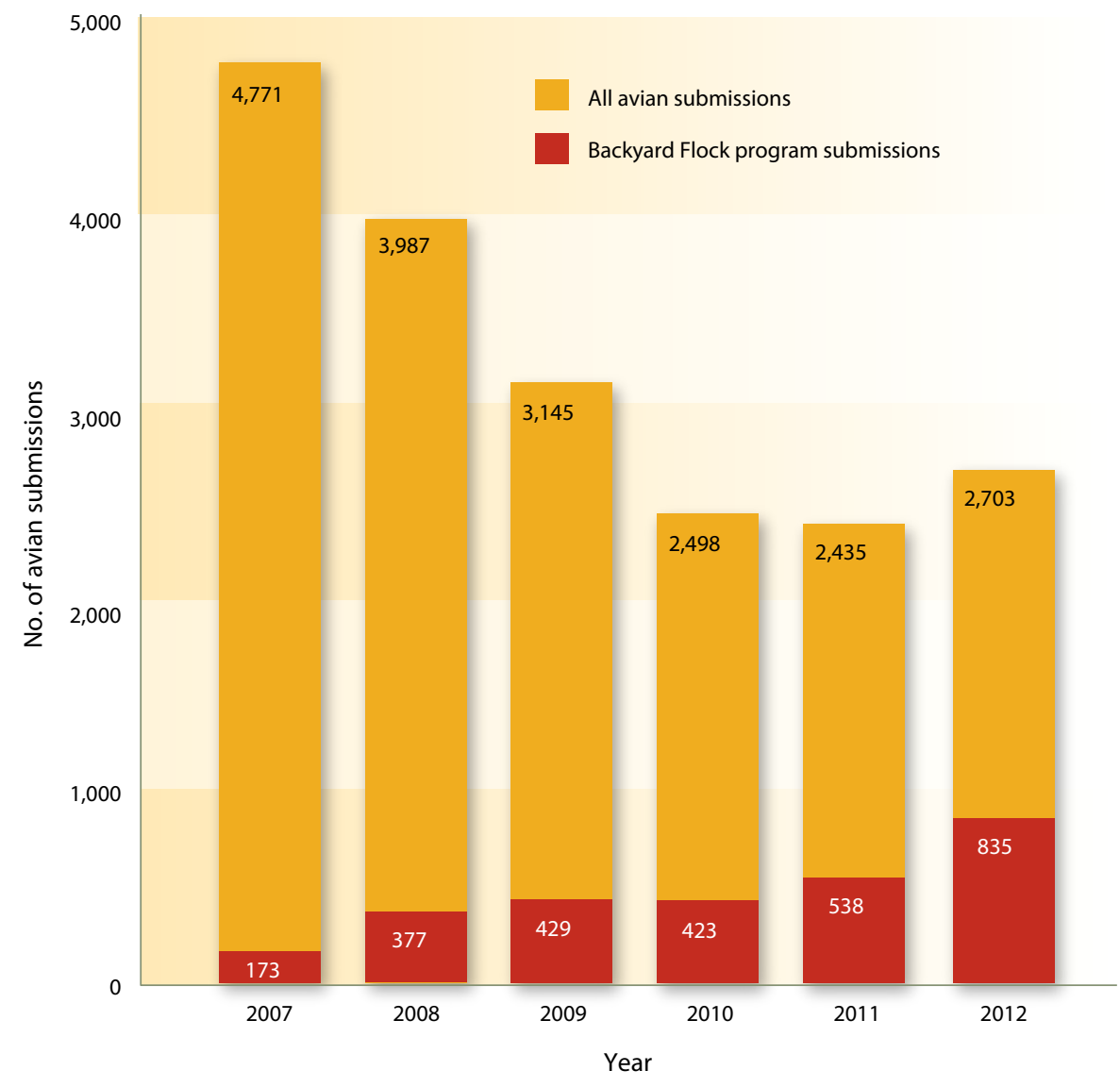

Fig. 1. Number of total avian and Backyard Flock submissions for necropsy examinations, 2007-2012. 
congenital malformations. Respiratory system diseases $(n=512)$ were aspiration pneumonia, rhinitis, sinusitis, airsacculitis, tracheitis, chronic respiratory disease, and pneumonia due to aspergillosis, Mycoplasma species, Avibacterium paragallinarum, Avibacterium gallinarum, E. coli, Klebsiella species, infectious bronchitis virus, inclusion body tracheitis, and infectious laryngotracheitis infections. Integumentary system diseases $(n=128)$ were cutaneous pox virus, ectoparasitism by lice and mites, and a few bacterial dermatitis or cellulitis cases. Musculoskeletal system diseases $(n=69)$ included arthritis, discospondylothesis, bone deformity, foot injury, myopathy, muscle necrosis (one reported cause was vitamin E deficiency), muscle neoplasm, rickets, and bone and musculoskeletal diseases where the most commonly isolated infectious agents were Staphylococcus species, Clostridium species and Pasteurella multocida. Nervous system diseases $(n=58)$ were caused by parasite migration (presumptive Baylisascaris species), listeriosis, aspergillosis, West Nile virus, bornavirus, peripheral neuropathy and congenital malformation. Urinary/ renal system diseases $(n=60)$ included infectious bronchitis virus, bacterial and fungal infections, neoplasia and renal gout. Reproductive tract diseases $(n=521)$ were omphalitis, salpingitis, peritonitis/ coelomitis mostly caused by E. coli and Gallibacterium anatis biovar haemolyticum, internal layer, egg bound, oviduct

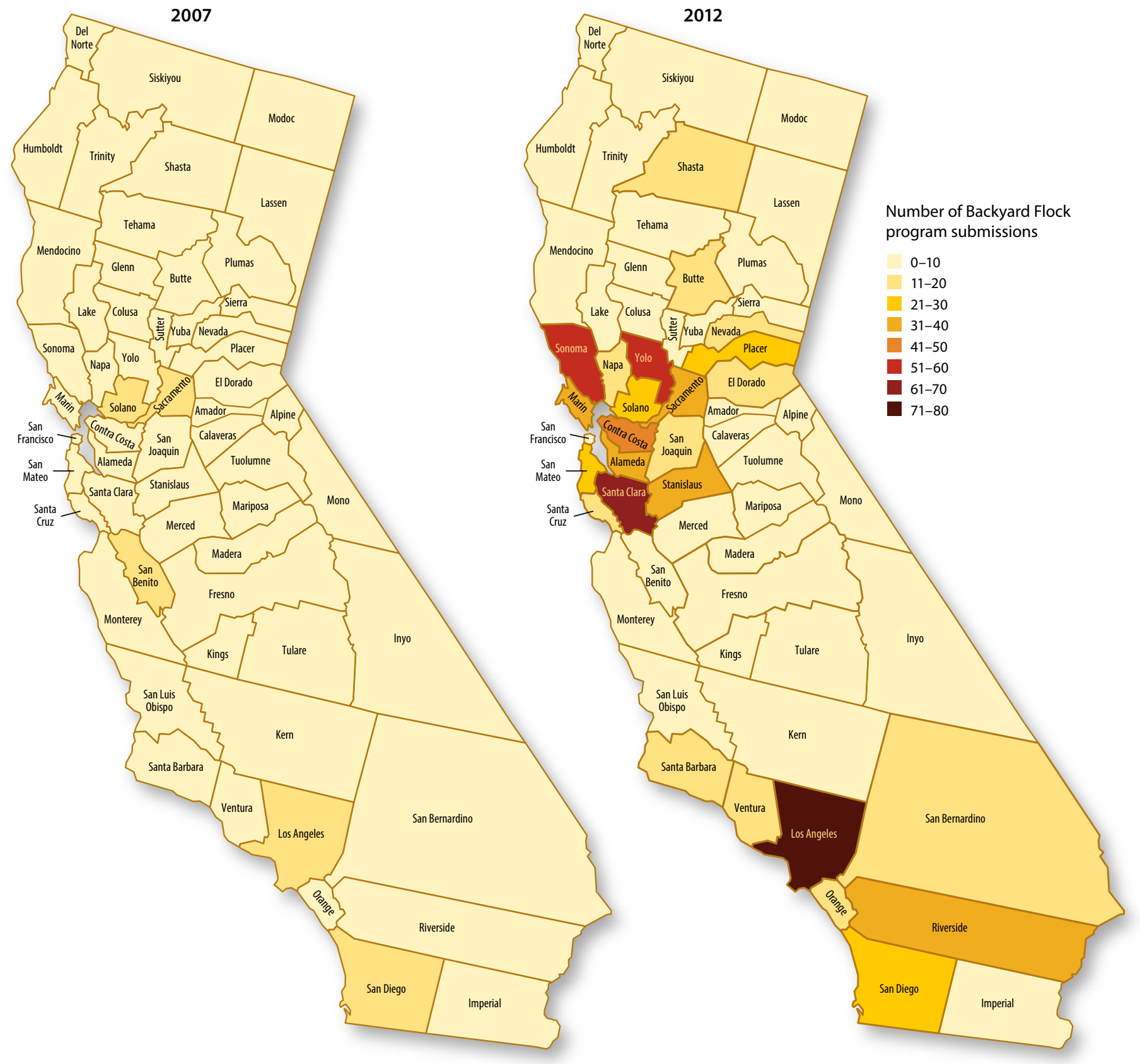

Fig. 2. Number of poultry submissions to the Backyard Flock necropsy program, by county in 2007 and 2012. 
prolapse, yolk sac disorders and neoplasia. Sensory (eye and ear) diseases $(n=23)$ were mostly due to bacterial infections. Endocrine system diseases and neoplasia $(n=4)$ and systemic diseases $(n=214)$ were primarily caused by the aforementioned etiologic bacterial, fungal or viral agents. Apart from starvation, emaciation, malnutrition, dehydration and obesity, the nutritional/toxicosis diseases $(n=97)$ were primarily toxicoses and comprised of botulism, anticoagulants, malathion, organophosphate, lead, copper, selenium, strychnine, vitamin A and zinc; riboflavin, vitamin $A$, vitamin $E$, zinc and selenium deficiencies also caused disease in $51.5 \%$ of nutritional conditions. Traumaassociated disease or death was primarily due to predation $(n=36)$.

\section{Program use, needs}

The increased popularity of keeping backyard chickens and the increased awareness of the free Backyard Flock program resulted in a $383 \%$ increase in necropsy submissions to the CAHFS laboratories over the 6 years. The $43 \%$ decline in the overall number of avian submissions from its peak in 2007 to 2012 demonstrates that the increase in Backyard Flock

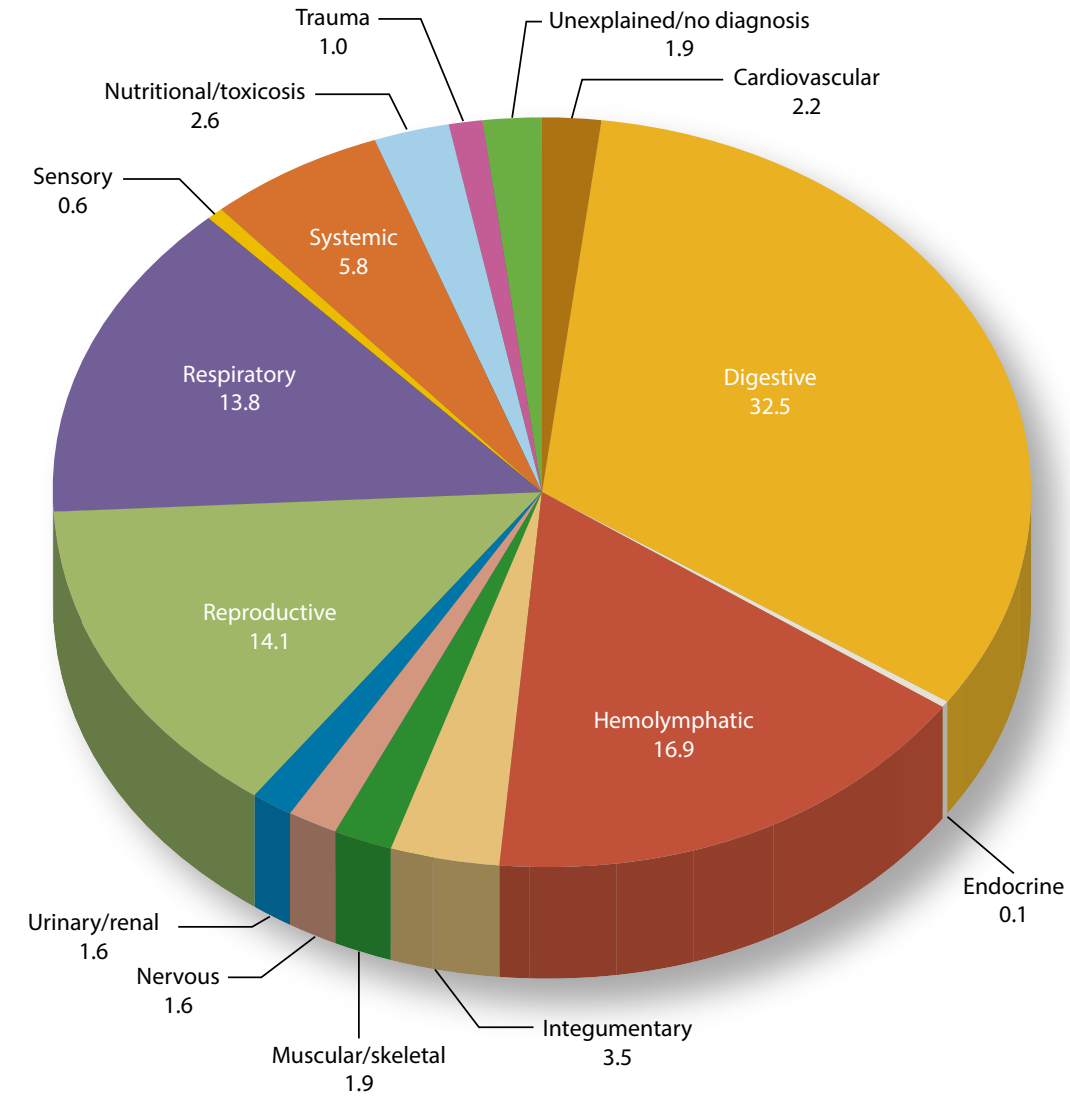

Fig. 3. Structured diagnoses of diseases from Backyard Flock necropsy examinations, 2007-2012, by category.

\section{Health programs, resources}

C

DFA has several avian health programs in place to assist the poultry industry in maintaining biosecurity and breeding standards, although many of them are focused on commercial poultry production, not backyard flocks. The National Poultry Improvement Plan (NPIP) is one such program; it helps to establish breeding standards and standards for hatcheries to prevent egg-transmitted and hatchery-disseminated diseases by monitoring certain diseases in flocks of producers who are participants in the program. The program is voluntary, costly and currently has only 15 California backyard flock participants (Monica Della Maggiore, NPIP, personal communication; Mattos 2012). The Quality Assurance Program (QAP), another voluntary program implemented by CDFA and managed by the California Poultry Health Board/NPIP, is targeted toward large commercial producers that seek to ensure food animal biosecurity and consumer protection. It has an extremely high percentage of participation, representing about $95 \%$ of California's commercial egg and poultry producers (CDFA 2012a).

CDFA recently published an information pamphlet specifically for owners or potential owners of backyard flocks that provides basic flock management information and explains how to recognize signs of illness (CDFA 2012b). UC Davis Department of Animal Science, UC Cooperative Extension, and the companion animal and pet exotics (CAPE) departments also have services and online resources to aid backyard poultry owners, including links to statistical information, disease control and biosecurity, and the CAHFS diagnostic laboratory system (Animal Science 2012). The university is also the location of the Davis branch of the CAHFS laboratory, where many of the tests for the NPIP and QAP programs are performed.

\section{For more information:}

\section{CDFA}

http://www.cdfa.ca.gov/ahfss/Animal_Health/Avian_Health_Program.html

\section{UC Agriculture and Natural Resources (ANR) publications} http://anrcatalog.ucdavis.edu/ltems.aspx?hierld=19250

\section{UC Cooperative Extension}

http://cecentralsierra.ucanr.edu/Livestock_and_Range_Management/Poultry_ Resources/

UC Davis Department of Animal Science http://animalscience.ucdavis.edu/Avian/

USDA

http://www.aphis.usda.gov/animal_health/birdbiosecurity/ 


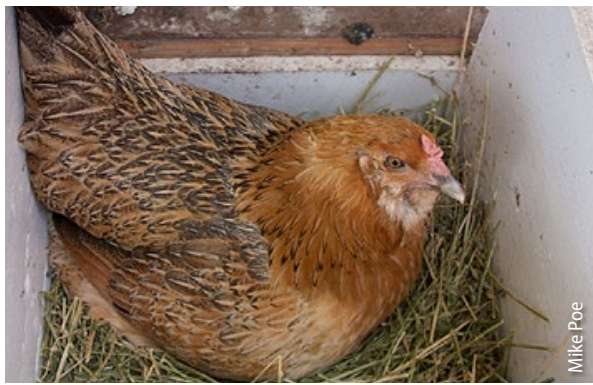

Chickens made up $91 \%$ of all Backyard Flock program submissions between 2007 and 2012.

submissions is significant and cannot be attributed to a general increase in avian submissions.

The county distribution data demonstrated a substantial increase in submissions in certain counties; however, there is a potential for bias in these results due to a variation in the ease of making a submission close to a CAHFS laboratory. While the cost of the necropsy is covered, shipping expenses are not. The cost of shipping and lack of easy access to a shipping facility may be deterrents to owners of flocks in more isolated areas, whereas owners in the vicinity of a CAHFS laboratory can simply drive their samples to the laboratory. This bias was demonstrated during the END outbreak of 2002-2003, when a spatial distribution study showed a strong correlation between proximity to a CAHFS laboratory and number of Backyard Flock necropsy submissions (Soberano et al. 2009).

The diagnostic data supports the finding that Marek's disease is the most commonly diagnosed disease throughout California. When introduced into an unvaccinated and previously unexposed flock, this disease causes depression, paralysis and death in up to $80 \%$ of birds. Marek's disease was also found to be the main disease in a recent retrospective study of chicken mortality focusing on flocks located specifically in Northern California (Mete et al. 2013), and SentiesCue and Charlton (2012) reported that Marek's disease accounted for $18.6 \%$ of all SDs from backyard poultry throughout the CAHFS laboratories in the past 10 years.

Website forums and blogs may offer convenient opportunities for discussion, but there is usually no screening to check the reliability of the information distributed among members, which has the potential to encourage misinformation and could lead to poor flock management

\section{Hotline for sick birds}

W

hat should you do if you find an unusual number of sick or dead hens in your poultry flock? If yours is a large-scale commercial operation, your company's manual probably advises: "Remove and isolate the affected birds; sanitize the area where they were found; have birds and environment tested by staff veterinarian."

But what if you've got a smaller operation with no in-house vet, or just a few backyard hens? According to California state veterinarian Annette Jones, DVM, you still need to take quick action. Ideally, you already have a relationship with a veterinarian familiar with poultry, so you should call her or him and describe the situation. But even if you do not have a poultry veterinarian, you can and should call the bilingual State Bird Hotline, 866-922-BIRD (922-2473). Poultry disease can travel fast, so it's essential that it be identified and controlled as quickly as possible, before it has a chance to spread to other flocks.

The hotline was established by the California Department of Food and Agriculture's Division of Animal Health and Food Safety Services (AHFSS) in recognition of the dual facts that poultry flocks are important to an increasing number of Californians, and that many flock owners aren't trained to recognize the signs of potentially devastating diseases.

The first thing you'll hear when you call the hotline is an automated answering system. After you choose to get information in Spanish or English, you can select one of the options - such as "report a sick or dead bird" or "learn how to recognize signs of disease." You are then connected to a staff veterinarian (or his or her voicemail) or to helpful recorded information. If you do get the voicemail, be assured that a veterinarian will call you back as soon as possible.

Speed here is definitely of the essence. Southern California's 2002 outbreak of exotic Newcastle disease showed that. The quicker a veterinarian can identify and control the disease, the fewer other birds will be affected, and the better off everyone will be.

Depending on circumstances, you may be instructed to contact one of the California Animal Health and Food Safety (CAHFS) laboratories directly for free diagnostic services or you may be visited by a veterinarian from one of four field offices located up and down the state who will help you determine what's wrong with your birds and what can be done to fix it. All of this is provided at no cost to you.

For more about the hotline and a wealth of information on poultry health, check out the AHFSS Avian Safety Program website: http:// www.cdfa.ca.gov/ahfss/Animal_Health/Avian_Health_Program.html.

\section{- W. J. Coats}

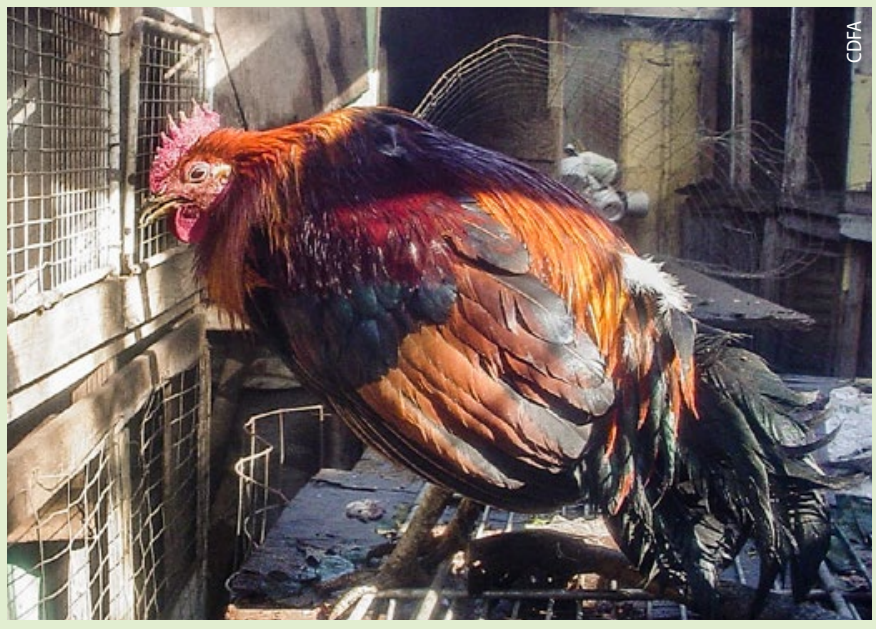

Chickens diagnosed with exotic Newcastle disease. Note the dropped head as evidence of depression, the swollen eyelid (above and right) and discharge from the mouth (right). The feathers are matted down and the hen hasn't been cleaning herself.

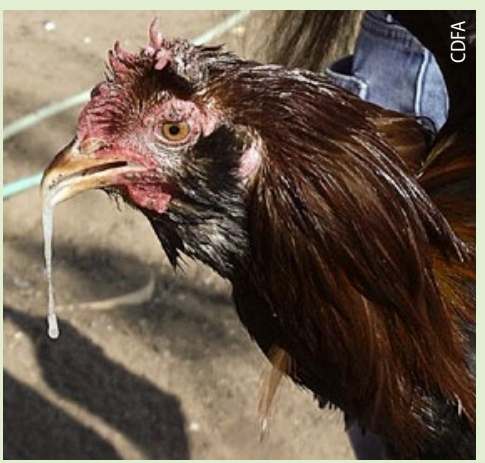


practices. CDFA has a strong incentive to provide reliable information but has seen a significant decrease in its funding, which has contributed to a reduction in outreach efforts. CAHFS and UC Cooperative Extension faculty routinely give public talks during related community events such as the Davis Tour de Cluck or the Heirloom Exposition in an
CAHFS Davis, personal communication). Funding for the Backyard Flock program is crucial in order to continue surveillance for important diseases such as HPAI and END while establishing information on flock distribution, size and encountered disease conditions, which is valuable for improved biosecurity and consumer safety, and is difficult to obtain in other

\section{Advertising state and federal avian health programs and providing incentives for backyard flock owners to use them would expand their effectiveness.}

effort to improve outreach. Nevertheless, the shortage of CDFA funds eventually may translate into a lack of disease surveillance and public awareness of biosecurity that, combined with owner noncompliance and lack of education, could contribute to an increased risk of disease.

As mentioned earlier, the federal and state programs that are in place are vastly underutilized by the backyard poultry community. After the END outbreak of 2002-2003, a study showed that fewer than $2 \%$ of backyard poultry owners interviewed were aware of the CAHFS Backyard Flock program and had submitted birds for testing (Soberano et al. 2009).

The estimated cost to CAHFS, and ultimately to CDFA, for performing each necropsy averages \$172 (Emily Sanson-Smith, ways. In addition, the low number (1.9\%) of cases in the unexplained death category indicates that valuable data was reliably obtained from the majority of cases, giving owners useful information on the health of their flock.

Advertising state and federal avian health programs and providing incentives for backyard flock owners to use them would expand their effectiveness. Also, public and privately run websites and forums might be encouraged to add links to government websites, programs and information, helping CDFA and USDA more effectively disseminate information and obtain data on backyard flocks. This would cost nothing but the time to network with the web hosts. Increased availability of online information from reliable sources could help to decrease the

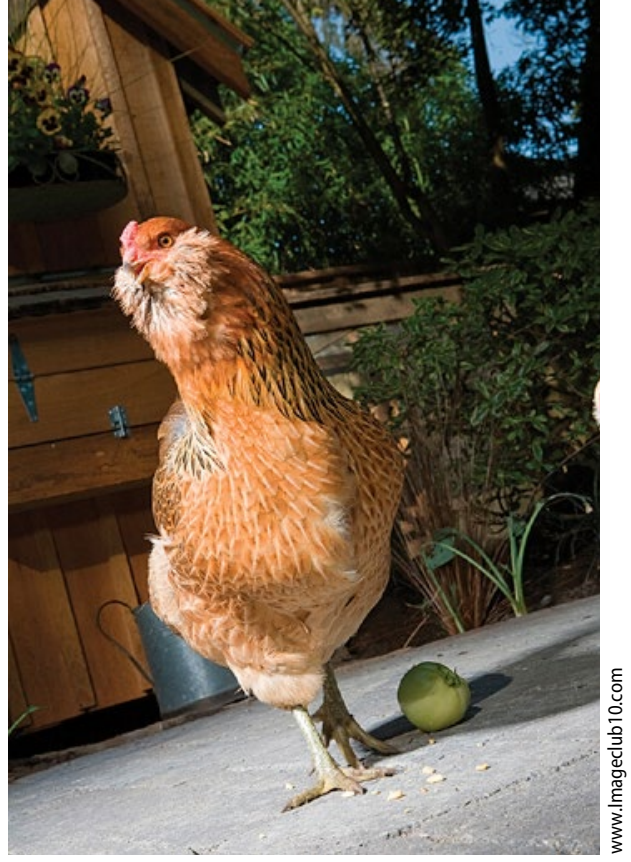

Marek's disease is the most commonly diagnosed cause of death in California poultry; when introduced into an unvaccinated flock, it can affect up to $80 \%$ of birds.

biosecurity risk presented by the increasing number of unregulated backyard flocks in California and nationwide.

S. Stinson is Laboratory Assistant and A. Mete is Assistant Professor of Clinical Diagnostic Pathology, California Animal Health and Food Safety Laboratory, School of Veterinary Medicine, UC Davis. We would like to thank CAHFS systemwide for their combined efforts in the Backyard Flock program, and Lucy Gomes, CAHFS Tulare IS staff, who was responsible for extracting the data for this study.

\section{References}

Animal Science, UC Davis. 2012. Avian science website. http://animalscience.ucdavis.edu/Avian/ (accessed July 1, 2012).

Arrington D. 2012. Seeds: More Sacramentans scratching out a place for chickens. Sacramento Bee. June 16, 2012. p 4.

Cary C. 2009. CLUCK presses for changes. Sacramento Press. August 6, 2009. www.sacramentopress.com/ headline/11610/CLUCK_presses_for_changes (accessed July 1, 2012)

[CDFA] California Department of Food and Agriculture. 2006. Foreign Animal Disease Response Network. www. cdfa.ca.gov/ahfss/Animal_Health/pdfs/Overview_FAD_ Response_1.pdf.

CDFA. 2012a. Quality Assurance Program. www.cdfa. ca.gov/is/cac/quality_assurance.html (accessed July 1 , 2012).

CDFA. 2012b. Eggsercise Book. With M. Pitesky. www.cdfa ca.gov/ahfss/ah/index.html (accessed July 1, 2012). Crespo R, Shivaprasad HL. 2008. Developmental, metabolic, and other noninfectious disorders. In: Saif YM (ed.). Diseases of Poultry. Ames IA: Wiley-Blackwell. p 1173-4.

Frawley K. 2013. Sacramento Backyard Poultry Group. www.meetup.com/sacramentobackyardpoultry/ (accessed March 20, 2013).

Garber L, Hill G, Rodriguez J, et al. 2007. Non-commercia poultry industries: Surveys of backyard and gamefowl breeder flocks in the United States. Prev Vet Med 80:120-8

Ludlow R. 2012. History of the Backyard Chickens website. www.backyardchickens.com/a/about-us (accessed July 1, 2012).

Mattos B. 2012. Hatcheries, dealers, and independent flocks participating in the national poultry improvement plan.www.aphis.usda.gov/animal_health/animal_dis_ spec/poultry/participants.shtml.

McBride M, Hird D, Carpenter T, et al. 1991. Health survey of backyard poultry and other avian species located within one mile of commercial California meat-turkey flocks. Avian Dis 35(2):403-7.

Mete A, Giannitti F, Barr B, et al. 2013. Causes of mortality in backyard chickens in Northern California: 2007-2011. Avian Dis 57:311-5.

Palermo B. 2010. Legal Stuff. www.salemchickens.com/ legalstuff.html (accessed July 1, 2012).
Pollock SL, Stephen C, Skuridina N, Kosatsky T. 2012. Raising chickens in city backyards: The public health role. J Commun Health 37:734-42.

Rosner B. 2000. Fundamentals of Biostatistics (5th ed.). Duxbury Thompson Learning, Boston, MA. p 395. Salkin P. 2011. Feeding the locavores, one chicken at a time. Zoning Planning Law Rep 34(3):1-12.

Senties-Cue G, Charlton B. 2012. 2001-2011 Poultry backyard diseases frequency in California. Proc 61st Western Poultry Disease Conference. 1-4 April, 2012. Scottsdale, AZ. p 119-20.

Soberano G, Carpenter T, Cardona C, Charlton C. 2009 Spatial distribution of free-of-charge pathology submissions to the California Animal Health and Food Safety Laboratories during the Exotic Newcastle outbreak in 2002-2003. Avian Dis 53:2-6.

Sunset Magazine. January 2011. Top 100 Cultural Trends Shaping the West. www.sunset.com/travel/ outdoor-adventure/cultural-trends-sunset-magazine-0211-00418000070383/page23.html (accessed July 1, 2012).

Torres T. 2012. About Us. My Pet Chicken website. www. mypetchicken.com/about-our-company/about-us.aspx (accessed July 1, 2012). 